Document downloaded from:

http://hdl.handle.net/10251/58840

This paper must be cited as:

Mota Babiloni, A.; Navarro Esbri, J.; Barragán Cervera, A.; Molés Ribera, F.; Peris Pérez, B. (2015). Analysis based on EU Regulation No 517/2014 of new HFC/HFO mixtures as alternatives of high GWP refrigerants in refrigeration and HVAC systems. International Journal of Refrigeration. 52:21-31. doi:10.1016/j.ijrefrig.2014.12.021.

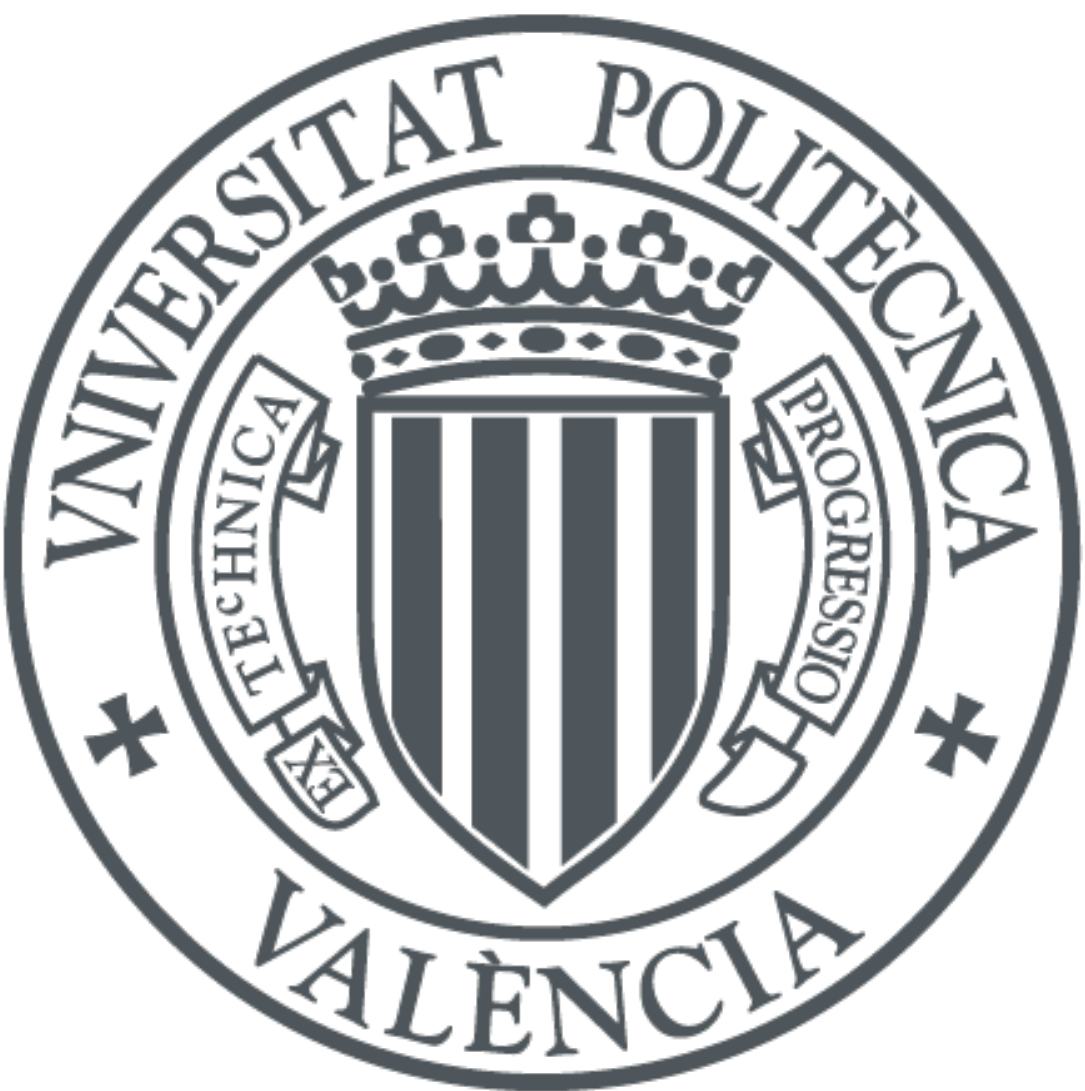

The final publication is available at

http://dx.doi.org/10.1016/j.jirefrig.2014.12.021

Copyright Elsevier

Additional Information 


\title{
Analysis based on EU Regulation No 517/2014 of new HFC/HFO mixtures as alternatives of high GWP refrigerants in refrigeration and HVAC systems.
}

Adrián Mota-Babiloni ${ }^{\text {a, b }}$, Joaquín Navarro-Esbrí ${ }^{a, ~ *}$, Ángel Barragán-Cervera ${ }^{\text {a }}$, Francisco Molés ${ }^{\text {a }}$, Bernardo Peris ${ }^{\text {a }}$

a ISTENER Research Group. Department of Mechanical Engineering and Construction, Campus de Riu Sec s/n, University Jaume I, E12071, Castellón (Spain).

${ }^{\mathrm{b}}$ Institute for Industrial, Radiophysical and Environmental Safety, Camino de Vera s/n, Polytechnic University of Valencia, E46022 Valencia, Spain.

\begin{abstract}
The EU Regulation No 517/2014 is going to phase-out most of the refrigerants commonly used in refrigeration and air conditioning systems (R134a, R404A and R410A) because of their extended use and their high GWP values. There are very different options to replace them; however, no refrigerant has yet imposed. In this paper we review and analyze the different mixtures proposed by the AHRI as alternative refrigerants to those employed currently. These mixtures are composed by HFC refrigerants: R32, R125, R152a and R134a; and HFO refrigerants: R1234yf and $\mathrm{R} 1234 \mathrm{ze}(\mathrm{E})$. It is concluded, from the theoretical analysis, that most of the new HFO/HFC mixtures perform under the HFC analyzed (although some experimental studies show the contrary) and, in most cases, do not meet the GWP restrictions approved by the European normative. Furthermore, some of the mixtures proposed would have problems due to their flammability.
\end{abstract}

Keywords: Refrigeration; Air conditioning; GWP; EU Regulation No 517/2014; HFO/HFC mixtures; HFC replacement.

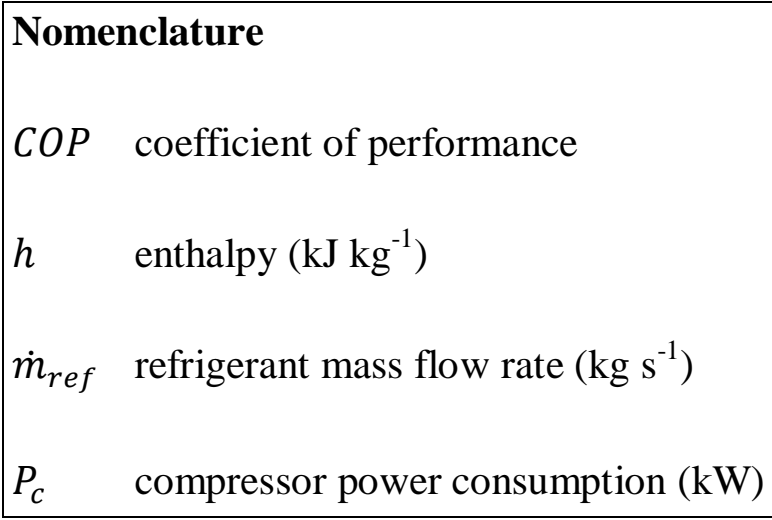

* Corresponding Author:

Tel: +34 964387529; fax: +34 964728106.

E-mail address: navarroj@uji.es 
$\dot{Q} \quad$ cooling capacity $(\mathrm{kW})$

SH Superheating Degree $\left({ }^{\circ} \mathrm{C}\right)$

$T \quad$ Temperature $\left({ }^{\circ} \mathrm{C}\right)$

$\dot{V}_{\text {ref }} \quad$ volumetric flow rate $\left(\mathrm{m}^{3} \mathrm{~h}^{-1}\right)$

Greek symbols

$\rho \quad$ density $\left(\mathrm{kg} \mathrm{m}^{-3}\right)$

Subscripts

in inlet

$k \quad$ condensation

o evaporator/evaporation

out outlet

suc compressor suction

Abbreviations

AC Air Conditioning

AHRI Air-Conditioning, Heating, and Refrigeration Institute

EOS Equation of State

GHG Greenhouse Gas

GWP Global Warming Potential

HFC HydroFluoroCarbon

HFO Hydrofluoroolefins

NBP Normal Boiling Point 
ODP Ozone Depletion Potential

PR-vdW Peng-Robinson EOS with van der Waals mixing rules

TEWI Total Equivalent Warming Impact

\section{Introduction}

In 1997, the countries that signed the Kyoto Protocol accorded to reduce the emissions of Greenhouse Gases (GHGs) [1]. Thus, HFC refrigerants were pointed as direct greenhouse gases because of their high Global Warming Potential (GWP) (though they have zero Ozone Depletion Potential, ODP), and the last environmental regulations are focused on phase-out these fluids.

First, the European Directive 2006/40/EC [2] was approved, affecting to refrigerants with GWP values above 150 used in mobile air conditioning systems (new systems from 2011 and the rest onward 2017). Then, the original F-gas Regulation was replaced by EU Regulation No 517/2014 [3]. The European Commission intention is to limit the total amount of the most important F-gases that can be sold in the EU from 2015 onwards and phasing them down in steps to one-fifth of 2014 sales in 2030. The limitations imposed by EU Regulation No 517/2014 are reproduced and summarized in Table 1. As can be seen, these prohibitions start at 2015 and finish in 2022, covering all refrigeration and air conditioning applications.

Table 1. Placing on the market prohibitions by the EU Regulation No 517/2014 [3].

R134a, R404A and R410A (GWP of 1430, 3922 and 2088 respectively [4]) are the refrigerants most affected by the regulation due to their common use in refrigeration and air conditioning applications, Table 2.

Table 2. Most commonly refrigerants used.

Additionally to the EU Regulation, some European countries have approved their own regulations to control direct GHG emissions [5]. Some countries have approved taxes on HFC acquisition [6]: for example, the R134a tax is $28.8 € / \mathrm{kg}$ in Denmark, $55.3 € / \mathrm{kg}$ in Norway, $35 € / \mathrm{kg}$ in Sweden, $6.5 € / \mathrm{kg}$ in Slovenia and $26 € / \mathrm{kg}$ in Spain. France, Poland and Sweden have proposed HFC taxes and Austria, Belgium, Germany, Netherlands, Switzerland and United Kingdom promote the use of climate friendly technologies.

Any refrigerant substitution that lowers overall efficiency is likely to have more adverse impact than benefit based on net global warming impacts (e.g., life-cycle GHG 
emissions or Total Equivalent Warming Impact, TEWI) [7]. So, besides looking for refrigerants that accomplish the GWP limitations, safe fluids that imply low energy consumption in vapour compression systems should be used [8].

There are different options to replace the refrigerants employed currently [9]: hydrocarbons, efficient but with high flammability [10][10]; natural refrigerants, highlighting ammonia [11] (R717) and $\mathrm{CO}_{2}$ (R744) in transcritical systems [12][12] or at the low stage in cascade systems with a synthetic refrigerant at the high stage [13]; and Hydrofluoroolefin (HFO) as pure refrigerants [14] or blends [15].

In this work different HFC/HFO mixtures (identified by the AHRI) are analyzed to replace HFC refrigerants (R134a, R404A and R410A) planned to be phased out in coming years by EU Regulation No 517/2014. The rest of the paper is organized as follows: In section 2, the effect of GWP limitations on HFC most commonly used are discussed. In section 3, the HFO/HFC mixtures selected and their former refrigerants are presented. In section 4, methodology and results of the theoretical analysis are shown. In section 5, a brief HFO/HFC mixtures review is performed. Finally, section 6 contains the main conclusions of the study.

\section{Analysis of GWP limitations imposed by EU Regulation No 517/2014}

In the following section the consequences of the GWP limitations imposed by the EU Regulation to the most commonly used refrigerants (in developed countries [16]) are analyzed attending to classification presented in Table 2.

\subsection{Limitations imposed to R134a}

$\mathrm{R} 134 \mathrm{a}(\mathrm{GWP}=1430)$ is used in domestic and medium temperature commercial applications. Its application in commercial applications is limited by its Normal Boiling Point (NBP), that is approximately $-26^{\circ} \mathrm{C}$ and at temperatures below of that, the system pressure is lower than the atmospheric.

The GWP limitation of 150 in domestic refrigeration will imply that European refrigerators that work with $\mathrm{R} 134 \mathrm{a}$ will change to isobutene with slight modifications [17] (In Europe, R134a and isobutane (R600a) are both used in these systems): R600a is cheap and works with best performance than other refrigerants [18] (even R134a [19]); and its use is recommended by environmental organizations [20]. Although R600a is a flammable refrigerant (classified as A3 by the ASHRAE), it can be used because the small refrigerant charge (generally less than $0.6 \mathrm{~kg}$ ).

R134a can be used until 2022 in commercial hermetically sealed equipment (GWP<2500), but not since 2022 (GWP>150). It is expected that the system/refrigerant combination that will be imposed in the market will depend on the flammability 
limitations. This limitation will imply important changes regarding to the actual situation.

For stationary refrigeration equipment $(\mathrm{GWP}<2500)$ the limitation will not present a problem for R134a systems.

In multipack centralised refrigeration systems (GWP<150), R134a could be used as primary refrigerant circuit of cascade systems, using $\mathrm{CO}_{2}(\mathrm{R} 744)$ in the low stage.

Although R134a can be used in some applications, it should be considered its replacement due to the high leakage rate of some systems [21] and the acquisition tax, existing in some developed countries [6]. Besides HFO/HFC mixtures, another interesting option is $\mathrm{CO}_{2}(\mathrm{GWP}=1)$ in a transcritical cycle [22].

\subsection{Limitations imposed to R404A}

$\mathrm{R} 404 \mathrm{~A}(\mathrm{GWP}=3922)$ is used in commercial applications for medium and low temperature refrigeration. In the case of low or medium and low (simultaneous) temperature refrigeration, R404A is usually selected as unique refrigerant. In the case of only medium temperature refrigeration requirements, R404A is the refrigerant used when the aim is to have low initial investment and R134a when higher energetic efficiencies are pursued, especially at high condensation temperatures.

R404A cannot be used in any of the commercial refrigeration applications considered by the Regulation due to its very high GWP (3922). In stationary refrigeration systems (GWP<2500), using R134a can be considered (or another non-flammable solution). Then, for multipack centralised refrigeration systems, the solution could be the same that exposed before (to use an $\mathrm{R} 134 \mathrm{a}-\mathrm{CO}_{2}$ cascade system).

It should be mentioned that, replacing R404A with R134a will imply a decrease in condensation pressures (for example, at $55^{\circ} \mathrm{C}$, R134a condensation pressure is $1491 \mathrm{kPa}$ whereas R404A condensation pressure is $2585 \mathrm{kPa}$ ) and the system will allow higher condensation temperatures. Furthermore, the R134a systems present lower discharge temperatures than R404A systems.

\subsection{Limitations imposed to $R 410$ A}

R410A (GWP=2088) can be found in chillers and air conditioning systems (movable or stationary). Although the GWP limitation for chillers will not be a problem (GWP<2500), it is going to be phased out in air conditioning applications.

In movable room air conditioning equipment $(\mathrm{GWP}<150)$, the refrigerant charge is lower than $1 \mathrm{~kg}$, thereby one option to be considered would be to reduce the refrigerant charge using flammable (R600a) or low flammable refrigerants (HFO). Nowadays does 
not exists any movable room air-conditioning equipment designed to work with GWP $<150$ non-flammable refrigerants, consequently it will be difficult to find efficient solutions in this case.

Finally, for single split air conditioning systems $(\mathrm{GWP}<750)$, there are different A1 mixtures that can replace R410A (or even R32 [23] even though using flammable refrigerants in applications could be a problem) without large modifications [24]. $\mathrm{CO}_{2}$ could be an alternative; however, this is not recommendable due to the lower energy efficiency presented in summer air conditioning conditions [25].

\section{HFC/HFO mixtures alternatives}

When mixing refrigerants some shortcomings of the former components are overcame [26]. Different investigations are carried out recently to characterize the mixtures and study its properties and performance.

\subsection{Alternatives selected}

The Air-Conditioning, Heating, and Refrigeration Institute (AHRI) began a collaborative investigation (with the support of various research groups) to study the behavior of the new fluorinated refrigerants [15]. The HFC/HFO mixtures alternatives identified by the American Heating (AHRI) are presented in Fig. 1 and their compositions are shown in Table 3. They are classified according to the refrigerant that it is intended to replace and their GWP values and their expected safety classification [27] are specified. The complete list of AHRI investigations is exposed and continuously updated [28].

Fig. 1. HFC/HFO mixture alternatives to R404A, R410A and R134a; and their GWP and safety classification.

Table 3. HFC/HFO Mixtures composition by mass percentage.

According to GWP values, all the R134a alternatives can be used in stationary refrigeration systems and in multipack centralised refrigeration systems in cascade systems. Besides, the flammable options, AC5 and ARM-42a can be used directly because their GWP is under 150. AC5, AC5X and ARM-41a possess high values of glide (and cannot be considered as near-azeotrope mixtures).

Although in stationary refrigeration systems all the R404A alternatives can be used (GWP<2500), in multipack centralised refrigeration systems for commercial use they should be used in cascade systems, because their GWP values are above 150 and below 
1500 (except ARM-32a whose GWP is upper 1500). All the refrigerants have a high values of glide (more than $5^{\circ} \mathrm{C}$ ) and the NBP are between $-42^{\circ} \mathrm{C}$ and $-38^{\circ} \mathrm{C}$ so they can be used in freezing applications, if the evaporation temperature are around $-35^{\circ} \mathrm{C}$.

Except L41, the rest of fluids are non-flammable mixtures and they present high values of glide (highlighting HDR1D). All of them can replace R410A in single split airconditioning systems and stationary refrigeration systems (in this case can also be used R410A, the final choice will depend of economic and environmental parameters) but not in movable room air-conditioning equipment. It is also considered R32 in the comparison because its GWP value is under the air-conditioning limitation of 750 .

Akasaka et al. [29] studied critical point parameters for the mixture R32/R1234yf. Then, Akasaka [30] developed models to predict R32/R1234ze(E) and R32/R1234yf properties. Hu et al. measured Vapor-Liquid Equilibrium (VLE) data for R1234yf mixed with R134a [31] and R152a [32], and then checked the values using the PengRobinson equation of state with the van der Waals mixing rules (EOS PR-vdW). Kamiaka et al. [33] extended the VLE study for mixtures of R1234yf with 32, R125 and R134a and also checked these values with the Peng-Robinson and Helmholtz EOS. Dong et al. [34] and Yang et al. [35] correlated the Peng-Robinson EOS with the mixtures R134a/R1234ze(E) and R152a/R1234ze(E).

\subsection{Former refrigerants}

The former refrigerants (fluids employed to compose the mixtures) are the HFC R32, R125, R134a, R152a; and the HFO R1234yf and R1234ze(E) (all of them with ODP=0). The mixtures properties are related to those of the former refrigerants and the final composition. The main characteristics of the former refrigerants are shown in Table 4.

Table 4. Main characteristics of base refrigerants.

While R152a is classified as A2 refrigerant by ASHRAE 34, R32 and the HFO R1234yf and R1234ze(E) are classified as A2L. R125 and R134a are the only non-flammable refrigerants. The refrigerants R125 and R134a have very high GWP values (3500 and 1430 respectively) and R32 is still above the most of GWP limitations. For low evaporating temperature necessities, the only refrigerants that have a boiling point below $-40^{\circ} \mathrm{C}$ are $\mathrm{R} 32$ and $\mathrm{R} 125$.

R32, R152a and R125 are used for refrigerant blends (R404A, R407C, R410A, etc.), used in different fields of refrigeration [36] and air conditioning [37], replacing R12 and $\mathrm{R} 22$. As seen before, R134a is used in most of the refrigeration applications: vehicle air conditioner, commercial and industrial cooling systems, and chillers. R1234yf is the 
refrigerant proposed to replace R134a in vehicle air conditioner [38] (even though another option is using $\mathrm{CO}_{2}$ [39]) and $\mathrm{R} 1234 \mathrm{ze}(\mathrm{E})$ in water-cooled chillers [40].

\section{Theoretical comparison}

\subsection{Methodology of comparison}

First, baseline refrigerants (R404A, R410A and R134a) are compared with the alternative refrigerants shown in Fig. 1 simulating a one-stage cycle (Fig. 2); then, the results found in recent research are discussed.

Fig. 2. Diagram and P-h cycle of one stage cycle.

In order to carry out the simulations, the operating temperatures (calculated according to Eq. (1) and (2) [41], taking into account glide considerations) are selected according to the typical commercially usage temperatures for the baseline refrigerants.

The evaporation temperatures selected for $\mathrm{R} 134 \mathrm{a}$ are $-15^{\circ} \mathrm{C}$ and $5^{\circ} \mathrm{C}$ (medium evaporation conditions) and the condensation temperatures are $30^{\circ} \mathrm{C}$ and $65^{\circ} \mathrm{C}(\mathrm{R} 134 \mathrm{a}$ can be used even in tropical temperatures showing acceptable energetic efficiency). The evaporation temperatures for $\mathrm{R} 404 \mathrm{~A}$ are $-35^{\circ} \mathrm{C}$ (freezing conditions) and $-5^{\circ} \mathrm{C}$ (refrigerating conditions limit) and the condensation temperatures are $30^{\circ} \mathrm{C}$ and $55^{\circ} \mathrm{C}$ (winter and summer conditions). The evaporation temperatures for $\mathrm{R} 410 \mathrm{~A}$ are $-10^{\circ} \mathrm{C}$ and $10^{\circ} \mathrm{C}$ (typical air conditioning evaporation temperatures) and the condensation temperatures are $30^{\circ} \mathrm{C}$ and $55^{\circ} \mathrm{C}$. The conditions are summarized in Table 5.

Table 5. Operating temperatures.

Moreover, the following assumptions are made:

- Pressure drops are neglected in heat exchangers and lines.

- Ideal compression (compressor efficiencies equal to 1).

- There is no heat transfer to the surroundings.

- Isenthalpic process is considered at the expansion valve.

- The superheating and the subcooling degree for baselines are $7^{\circ} \mathrm{C}$ and $2^{\circ} \mathrm{C}$, respectively. For the rest, a correction is applied [41], Eq. 3.

- The thermodynamic states of refrigerants are calculated using REFPROP v.9.1 [42] (this program uses the most accurate and recent equations of state and models currently available). 


$$
\begin{aligned}
T_{o} & =\frac{1}{3} T_{\text {Bubble }}+\frac{2}{3} T_{\text {Dew }} \\
T_{k} & =\frac{1}{2} T_{\text {Bubble }}+\frac{1}{2} T_{\text {Dew }} \\
\text { SH } H_{\text {alternative }} & =S H_{\text {baseline }}-\frac{1}{3} \text { Glide }_{\text {baseline }}
\end{aligned}
$$

The energetic parameters considered in the comparison are cooling capacity, $\dot{Q}_{o}$, (Eq. (4)) and Coefficient of Performance (Eq. (5)), COP. The compressor power consumption, $P_{c}$, is obtained using the Eq. (6).

$$
\begin{gathered}
\dot{Q}_{o}=\dot{m}_{r e f}\left(h_{\text {out }}-h_{\text {in }}\right)_{o} \\
C O P=\dot{Q}_{o} / P_{c} \\
P_{c}=\dot{m}_{r e f}\left(h_{\text {out }}-h_{\text {in }}\right)_{c}
\end{gathered}
$$

In order to obtain the theoretical mass flow rate, $\dot{m}_{\text {ref }}$, a volumetric flow rate of $0.00653 \mathrm{~m}^{3} \mathrm{~s}^{-1}$ is considered at compressor suction (this is a typical value for scroll compressors used in air conditioning and small refrigeration systems), Eq. (7).

$$
\dot{m}_{\text {ref }}=\left(\dot{V}_{\text {ref }} \rho\right)_{\text {suc }}
$$

The results are shown as a relative deviation from baselines R134a, R410A and R404A $\left(\% \dot{Q}_{o}\right.$ and $\left.\% C O P\right)$, Eq. (8) and (9).

$$
\begin{gathered}
\% \dot{Q}_{o}=\frac{\dot{Q}_{o, \text { alternative }}-\dot{Q}_{o, \text { baseline }}}{\dot{Q}_{o, \text { baseline }}} 100 \\
\% C O P=\frac{\text { COP } P_{\text {alternative }}-C O P_{\text {baseline }}}{C O P_{\text {baseline }}} 100
\end{gathered}
$$

\subsection{R134a alternatives results}

The cooling capacity and COP comparison can be seen in Fig. 3. AC5, ARM-41a, AC5 and ARM-42a present higher cooling capacity than R134a (being ARM-41a the refrigerant with highest deviation values, between 7 and 10\%). For these refrigerants, the deviation is higher at low evaporation temperature and low condensation temperature. D-4Y, XP-10 and N13 cooling capacities are under those obtained using R134a (N13 shows the lowest values). Contrary to commented before, the lower difference between these refrigerants and R134a occurs at high evaporation temperature. 
All the refrigerants perform worse than R134a. In general, the energetic results are better for replacements at higher evaporation temperatures (except AC5X, ARM-41a and AC5) and lower condensation conditions (except AC5). The best performing replacement is AC5 (at $T_{o}=-15^{\circ} \mathrm{C}$ and $T_{k}=65^{\circ} \mathrm{C}$ its COP is slightly higher than R134a) and the following refrigerants are AC5X, ARM-41a and N13. The refrigerants that present highest deviation are D-4Y and XP-10 (until -8\%).

Fig. 3. Results compared with R134a: a) cooling capacity and b) COP.

\subsection{R404A alternatives results}

As it is shown in Fig. 4.a), all the refrigerants present a diminution in cooling capacity at low condensation temperatures (affected by the compression ratio). Then, at high condensation temperatures their cooling capacity is higher (except for ARM-30a and ARM-31a). The mixtures with highest deviation from R404A are ARM-32a, N40 and L40.

Due to the alternatives minor power consumption, COP results for alternatives are higher than R404A. So, all the replacements performs better (or similar at low condensation temperatures) that R404A. There is a better improvement in COP for freezing applications $\left(-35^{\circ} \mathrm{C}\right)$ than for refrigerating applications $\left(-5^{\circ} \mathrm{C}\right)$. In this case, the best options are ARM-30a, ARM-31a, D2Y65 and DR-7.

Fig. 4. Results compared with R404A: a) cooling capacity and b) COP.

\subsection{R410A alternatives results}

Fig. 4 presents cooling capacity and COP comparison taking R410A as baseline. All the mixtures exhibit lower cooling capacity than R410A (only if pure R32 is considered, higher cooling capacity values are observed). The mixture with lowest $\dot{Q}_{o}$ values is D2Y60 (around -30\%) and the nearest cooling capacity values to R134a are presented by HPR1D (between -5 and 1\%) and then, DR-5 and L41. Highest cooling capacity results for alternatives occur at high evaporation and condensation temperatures.

Concerning to the energetic efficiency comparison, based on COP, the results are positive for alternatives in all cases except at $T_{o}=10^{\circ} \mathrm{C}$ and $T_{k}=30^{\circ} \mathrm{C}$. Contrary to that observed before, highest COP results are exhibit at low evaporation temperature conditions. Best results are presented by ARM-70a, D2Y60 and DR-5 (until 9\% higher). The lower results are observed considering HPR1D (although at $T_{o}=-10^{\circ} \mathrm{C}$ and $T_{k}=55^{\circ} \mathrm{C}$ 
its $\mathrm{COP}$ is approximately $6 \%$ higher than $\mathrm{R} 410 \mathrm{~A}$, at $T_{o}=-15^{\circ} \mathrm{C}$ and $T_{k}=65^{\circ} \mathrm{C}$ is $4 \%$ lower).

Fig. 5. Results compared with R410A: a) cooling capacity and b) COP.

\section{Experimental comparison based on literature}

In this section, the experimental comparisons available in the literature using $\mathrm{HFC} / \mathrm{HFO}$ mixture as alternative to R134a, R404A and R410A are revised to enrich the theoretical results presented before.

\subsection{R134a replacements}

XP-10 shows similar energy efficiency values when replace R134a in medium temperature circuit of hybrid cascade systems (using $\mathrm{CO}_{2}$ in low temperature circuit) [43]. N13 presents also similar efficiency to R134a when tested in an existing centrifugal chiller [44] and in vapour compression plant [45].

According to AHRI research, in a water-cooled chiller [46], XP-10 and ARM-42a cooling capacity is similar to those performed by R134a. Additionally, in a commercial bottle cooler/freezer [47], the average cooling capacity for XP-10 and N13 were 7.8 and 5.2\% lower than R134a, and the average COP were 9.7 (XP-10) and 5.7\% (N13) lower.

In bus air-conditioning unit designed [48]0, while the difference in COP between N13 and R134a was insignificant, between AC5 and R134a was worse down to $11 \%$. In an air-cooled screw chiller [49], the capacity of ARM-42a was very similar to R134a (at high ambient air temperature conditions). However, the efficiency of the chiller using ARM-42a was around 4\% lower than that of R134a.

\subsection{R404A replacements}

Mota-Babiloni et al. [50] obtained good performance results for different R404A replacement mixtures (HFC and HFO/HFC). In a reach-in freezer [43], the DR-7 energy consumption compared to R404A was between 3 and 8\% lower for DR-7 and between 0 and $4 \%$ lower for DR-33. In display case (condensing unit), DR-33 energy consumption was between 3 and 4\% lower at low temperature and between 8 and 12\% lower at medium temperature conditions.

For commercial refrigeration systems [51], N40 energy efficiency is higher than that of L40, being that higher than R404A. The difference between R404A and its alternatives is increased at low evaporation temperatures. N40 cooling capacity is slightly higher than R404A but for L40, this parameter is lower. In a reciprocating compressor freezer 
application [52], L40 and DR-7 perform better than R404A and DR-7 showed higher capacity compared to L40. N40 energy consumption is lower than R404A.

The AHRI most significant tests shown are as follows: in a trailer refrigeration unit designed for R404A [53], the cooling capacity was down to $21 \%$ for L40, down to $19 \%$ for ARM-30a and comparable for DR-7 at low return air temperatures. At higher return air temperatures the cooling capacity was comparable to R404A or up to $10 \%$ for L40, up to $5 \%$ for ARM-30a and up to $11 \%$ to for DR-7. In a system drop-in test of L40, L41 and N40 in ice machines [54], the best performing refrigerant was N40. It has shown good capacity (over the full range of operating conditions) and good energy efficiency.

The rest of results presented by the AHRI, as compressor calorimeter tests, can be found in [28].

\subsection{R410A replacements}

Honeywell suggests that the global efficiency of stationary reversible Air Conditioning (AC) systems using their mixture, L41, will be higher than R410A with an optimized compressor, typically at high RPM and high ambient temperature [55]. DR-5 COP compared to R410A was between -2 to $4 \%$ (including cooling and heating) in a mini split RAC and up to $7 \%$ (cooling mode) and up to $22 \%$ (heating mode) in a ducted AC system [43].

Another studies comprised in AHRI coordinated program was the following: some simulations validated with experimental tests showed that D2Y60 capacities and COPs were lower than R410A and R32 [56], L41 is superior compared to R410A in regards to COP [57] and Schultz [58] claims that the best substitute of R410A in a small air-cooled water chiller / heat pump is DR-5 because offers characteristics very similar to R410A, lower operating pressures, lower GWP, and likely lower flammability than R32. Most of the options performed significantly lower in both cooling and heating capacity than R410A in split system heat pump [59].

\section{Conclusion}

This paper analyses the GWP limitations imposed by the EU Regulation No 517/2014 GWP, studying the opportunities offered by the new HFC/HFO mixtures as R134a, $\mathrm{R} 404 \mathrm{~A}$ and R410A replacements. This Regulation is going to affect intensely to the refrigerants and systems used nowadays in the refrigeration and air conditioning systems. The main conclusions of the study are the following ones.

Although a lower reduction in GWP is achieved (and consequently GWP tax) using low-flammable alternatives, only non-flammable refrigerants can be used in direct expansion systems in large consumption applications. The low-flammable alternatives 
could be used in primary circuit of secondary systems, high-stage of cascade systems or low charge applications (domestic refrigeration or air-conditioning).

The theoretical energy efficiency of R134a alternatives is under that obtained using $\mathrm{R} 134 \mathrm{a}$. The best option to substitute R134a is AC5; it presents the highest COP results, higher cooling capacity and a GWP value below 200. Among the non-flammable options, best results (cooling capacity and COP) are observed for ARM-41a (even though its GWP value is the higher than the rest of R134a alternatives).

N40 is the most promising alternatives to R404A if medium GWP values are allowed (cascade systems). L40 shows also higher cooling capacity in some cases and good energetic performance values. According to the strong GWP limitations, the best option seems to be replace the old systems with $\mathrm{CO}_{2}$ systems in commercial refrigerating systems (transcritical or at the low-stage of cascade).

When considering the best theoretical combination of cooling capacity/COP results, the most attractive mixture alternatives to R410A are DR-5 (non-flammable) and L41 (if flammable refrigerants are allowed or the refrigerant charge is minor).

Experimental studies reviewed show good results for N13, XP-10 and ARM-42a when substituting R134a. Again based on experimental comparisons, N40, L40 and DR-7 are good alternatives for R404A in terms of energy efficiency; and L41 and DR-5 can be suitable replacements for R410A.

Although several chemical companies have developed different HFC/HFO mixtures, these refrigerants do not provide a definitive solution because they have yet restrictions as flammability or GWP values above that fixed as maximum by EU Regulation (the value chosen at 150 seems to be very strict). Moreover, in some cases, the performance is below the refrigerants employed currently. More property studies are needed to characterize properly the mixture refrigerants behavior.

\section{Acknowledgements}

The authors thankfully acknowledge "Ministerio de Educación, Cultura y Deporte" for supporting this work through "Becas y Contratos de Formación de Profesorado Universitario del Programa Nacional de Formación de Recursos Humanos de Investigación del ejercicio 2012”.

\section{References}

[1] UN. Kyoto Protocol to the United Nations framework convention on climate change (1997). New York, NY, USA.

[2] Directive 2006/40/EC of The European Parliament and of the Council of 17 May 2006 relating to emissions from air conditioning systems in motor vehicles 
and amending Council Directive 70/156/EC. Official Journal of the European Union (2006).

[3] Regulation (EU) No 517/2014 of the European Parliament and the Council of 16 April 2014 on fluorinated greenhouse gases and repealing Regulation (EC) No 842/2006. Official Journal of the European Union (2014).

[4] S. Solomon, D. Qin, M. Manning, Z. Chen, M. Marquis, K.B. Averyt, M. Tignor, H.L. Mille. Contribution of Working Groups I, II and III to the Fourth Assessment Report of the Intergovernmental Panel on Climate Change (2007). Cambridge University Press: Cambridge, United Kingdom and New York, NY, USA.

[5] M. Thompson. Climate Change Regulation and the Next Generation of Refrigerants (2014). Retrieved online at: http://www.trane.com/commercial/uploads/pdf/cso/138/Refrigerants.pdf, 22 July 2014.

[6] A. Maratou. EU policy update - F-Gas Regulation, HFC taxes \& fiscal incentives for natural refrigerants. In: ATMOsphere Asia 2014 - Technology \& Innovation, 3-5 February 2015, Tokyo, Japan.

[7] J.M. Calm. Emissions and environmental impacts from air-conditioning and refrigeration systems. International Journal of Refrigeration 25 (2002), 293-305.

[8] J.M. Calm. The next generation of refrigerants - historical review, considerations, and outlook. International Journal of Refrigeration 31 (2008), $1123-1133$.

[9] M. Mohanraj, S. Jayaraj, C. Muraleedharan. Environment friendly alternatives to halogenated refrigerants-A review. International Journal of Greenhouse Gas Control 3 (2009), 108-119.

[10] B. Palm. Hydrocarbons as refrigerants in small heat pump and refrigeration systems - A review. International Journal of Refrigeration 31 (2008), 552-563.

[11] A. Pearson. Refrigeration with ammonia. International Journal of Refrigeration 31 (2008), 545-551.

[12] Y. Ma, Z. Liu, H. Tian. A review of transcritical carbon dioxide heat pump and refrigeration cycles. Energy 55 (2013), 156-172.

[13] A. da Silva, E.P. Bandarra Filho, A.H. Pontes Antunes. Comparison of a R744 cascade refrigeration system with R404A and R22 conventional systems for supermarkets. Applied Thermal Engineering 41 (2012), 30-35.

[14] A. Mota-Babiloni, J. Navarro-Esbrí, Á. Barragán, F. Molés, B. Peris. Drop-in energy performance evaluation of R1234yf and R1234ze(E) in a vapor compression system as R134a replacements. Applied Thermal Engineering 71 (2014), 259-265.

[15] K. Schultz, S. Kujak. System Drop-In Tests of R134a Alternative Refrigerants (ARM-42a, N-13a, N-13b, R-1234ze(E), and OpteonTMXP10) in a 230-RT Water-Cooled Water Chiller. Air-Conditioning, Heating, and Refrigeration Institute (AHRI) Low-GWP Alternative Refrigerants Evaluation Program (LowGWP AREP), TEST REPORT \#7 (2013). 
[16] Z. Yang, X. Wu. Retrofits and options for the alternatives to HCFC-22. Energy 59 (2013), 1-21.

[17] M.M. Joybari, M.S. Hatamipour, A. Rahimi, F.G. Modarres. Exergy analysis and optimization of R600a as a replacement of R134a in a domestic refrigerator system. International Journal of Refrigeration 36 (2013), 1233-1242.

[18] Y.S. Lee, C.C. Su. Experimental studies of isobutane (R600a) as the refrigerant in domestic refrigeration system. Applied Thermal Engineering 22 (2002), 507519.

[19] Danfoss. Practical Application of Refrigerant R600a Isobutane in Domestic Refrigerator Systems (2000). Retrieved online at: http://www.nt.ntnu.no/users/skoge/bookcep/diagrams/additional diagrams/more on refrigerants/isobutane(R600A)Danfos.pdf. 22 September 2014.

[20] J. Maté, C. Papathanasopoulos, S. Latif. Cool Technologies: Working with HFCs (2012). Retrieved online at: http://www.greenpeace.org/international/Global/international/publications/clima te/2012/Fgases/Cool-Technologies-2012.pdf, 25 July 2014.

[21] I.P. Koronaki, D. Cowan, G. Maidment, K. Beerman, M. Schreurs, K. Kaar, I. Chaer, G. Gontarz, R.I. Christodoulaki, X. Cazauran. Refrigerant emissions and leakage prevention across Europe - Results from the RealSkillsEurope project. Energy 45 (2012), 71-80.

[22] L. Cecchinato, M. Corradi, S. Minetto. Energy performance of supermarket refrigeration and air conditioning integrated systems working with natural refrigerants. Applied Thermal Engineering 48 (2012), 378-391.

[23] L. Cremaschi, X. Wu, A. Biswas, P. Deokar. Experimental study of compressor operating characteristics and performance when using refrigerants R32, R1234yf, and two new low GWP developmental refrigerants as drop-in replacements for R410A. In: 8th International Conference on Compressors and their Systems, 910 September 2013, City University London, London, United Kingdom.

[24] X.H. Han, Y. Qiu, P. Li, Y.J. Xu, Q. Wang, G.M. Chen. Cycle performance studies on HFC-161 in a small-scale refrigeration system as an alternative refrigerant to HFC-410A. Energy and Buildings 44 (2012), 33-38.

[25] Y.B. Tao, Y.L. He, W.Q. Tao. Exergetic analysis of transcritical CO2 residential air-conditioning system based on experimental data. Applied Energy 87 (2010), 3065-3072.B. Kulcar, D. Goricanec, J. Krope. Economy of replacing a refrigerant in a cooling system for preparing chilled water. International Journal of Refrigeration 33 (2010), 989-994.

[26] I. Sarbu. A review on substitution strategy of non-ecological refrigerants from vapour compression-based refrigeration, air-conditioning and heat pump systems. International Journal of Refrigeration 46 (2014), 123-141.

[27] American Society of Heating, Refrigerating and Air-Conditioning Engineers. ANSI/ASHRAE Standard 34, Designation and Safety Classification of Refrigerants (2013). 
[28] K. Hickman. Reference List for low GWP Refrigerants Testing AirConditioning, Heating, and Refrigeration Institute (AHRI) Low-GWP Alternative Refrigerants Evaluation Program (Low-GWP AREP), Literature Review (2013).

[29] R. Akasaka, K. Tanaka, Y. Higashi. Measurements of saturated densities and critical parameters for the binary mixture of 2,3,3,3-tetrafluoropropene ( $\mathrm{R}$ 1234yf) + difluoromethane (R-32). International Journal of Refrigeration 36 (2013), 1341-1346.

[30] R. Akasaka. Thermodynamic property models for the difluoromethane (R-32) + trans-1,3,3,3-tetrafluoropropene (R-1234ze(E)) and difluoromethane $+2,3,3,3$ tetrafluoropropene (R-1234yf) mixtures. Fluid Phase Equilibria 358 (2013), 98104.

[31] P. Hu, L.X. Chen, Z.S Chen. Vapor-liquid equilibria for the 1,1,1,2tetrafluoroethane (HFC-134a) + 1,1,1,2,3,3,3-heptafluoropropane (HFC-227ea) and 1,1,1-trifluoroethane (HFC-143a) + 2,3,3,3-tetrafluoroprop-1-ene (HFO1234yf) systems. Fluid Phase Equilibria 360 (2013), 293-297.

[32] P. Hu, L.X. Chen, W.B Zhu, L. Jia, Z.S. Chen. Isothermal VLE measurements for the binary mixture of 2,3,3,3-tetrafluoroprop-1-ene (HFO-1234yf) + 1,1difluoroethane (HFC-152a). Fluid Phase Equilibria. Fluid Phase Equilibria 373 (2014), 80-83.

[33] T. Kamiaka, C. Dang, E. Hihara. Vapor-liquid equilibrium measurements for binary mixtures of R1234yf with R32, R125, and R134a. International Journal of Refrigeration 36 (2013), 965-971.

[34] X. Dong, H. Guo, M. Gong, Z. Yang, J. Wu. Measurements of isothermal (vapour + liquid) equilibria data for $\{1,1,2,2$-Tetrafluoroethane $(\mathrm{R} 134 \mathrm{a})+$ trans1,3,3,3-tetrafluoropropene $(\mathrm{R} 1234 \mathrm{ze}(\mathrm{E}))\}$ at $\mathrm{T}=(258.150$ to 288.150$) \mathrm{K}$. The Journal of Chemical Thermodynamics 60 (2013), 25-28.

[35] Z. Yang, M. Gong, H. Guo, X. Dong, J. Wu. Phase equilibrium for the binary mixture of \{1,1-difluoroethane (R152a+ trans-1,3,3,3-tetrafluoropropene (R1234ze (E)) $\}$ at various temperatures from 258.150 to 288.150 K. Fluid Phase Equilibria 355 (2013), 99-103.

[36] B. Kulcar, D. Goricanec, J. Krope. Economy of replacing a refrigerant in a cooling system for preparing chilled water. International Journal of Refrigeration 33 (2010), 989-994.

[37] J. Wu, Y. Chu, J. Hu, Z. Liu. Performance of mixture refrigerant $\mathrm{R} 152 \mathrm{a} / \mathrm{R} 125 / \mathrm{R} 32$ in domestic air-conditioner. International Journal of Refrigeration 32 (2009), 1049-1057.

[38] S. Bobbo, C. Zilio, M. Scattolini, L. Fedele. R1234yf as a substitute of R134a in automotive air conditioning. Solubility measurements in two commercial PAG oils. International Journal of Refrigeration 40 (2014), 302-308.

[39] T. Tamura, Y. Yakumaru, F. Nishiwaki. Experimental study on automotive cooling and heating air conditioning system using $\mathrm{CO} 2$ as a refrigerant. International Journal of Refrigeration 28 (2005) 1302-1307. 
[40] K. Ueda, Y. Hasegawa, K. Wajima, M. Nitta, Y. Kamada, A. Yokoyama. Deployment of a New Series of Eco Turbo ETI Chillers. Mitsubishi Heavy Industries Technical Review 49 (2012), 58-63.

[41] Honeywell. Technology issues regarding Blends of Refrigerants 2012. Retrieved online at: http://www.honeywellrefrigerants.com/europe/?document=honeywell-blends-technology-issues-2012presentation\&download=1, 1 October 2013.

[42] E.W. Lemmon, M.L. Huber, M.O. McLinden. NIST Standard Reference Database 23: Reference Fluid Thermodynamic and Transport PropertiesREFPROP, Version 9.1. National Institute of Standards and Technology, Standard Reference Data Program, Gaithersburg, MD, USA, 2013.

[43] B. Minor, T. Leck. Update on DuPont Low GWP HFO-Based Technologies. In: OzonAction Webinar, 14 August 2013.

[44] S.F. Yana Motta. Low-GWP Refrigerants for Air Conditioinng and Refrigeration Applications. Retrieved online at: http://www.unep.org/ozonaction/Portals/105/documents/virtualexpo/IIIHoneywell_Samue1\%20Yana-Motta.pdf, 8 September 2014.

[45] A. Mota-Babiloni, J. Navarro-Esbrí, Á. Barragán-Cervera, F. Molés, B. Peris. Experimental study of an R1234ze/R134a mixture (R450A) as R134a replacement. International Journal of Refrigeration (2014. Retrieved online at: http://dx.doi.org/10.1016/j.ijrefrig.2014.12.010, 21 December 2014.

[46] K. Schultz, S. Kujak. System Drop-In Tests of R134a Alternative Refrigerants (ARM-42a, N-13a, N-13b, R-1234ze(E), and OpteonTM XP10) in a 230-RT Water-Cooled Water Chiller. Air-Conditioning, Heating, and Refrigeration Institute (AHRI) Low-GWP Alternative Refrigerants Evaluation Program (LowGWP AREP), TEST REPORT \#7 (2013).

[47] D. Shapiro. System Drop-In Tests of R-134a, R-1234yf, OpteonTM XP10, R1234ze(E), and N13a in a Commercial Bottle Cooler/Freezer. Air-Conditioning, Heating, and Refrigeration Institute (AHRI) Low-GWP Alternative Refrigerants Evaluation Program (Low-GWP AREP), TEST REPORT \#8 (2013).

[48] M. Kopecka, M. Hegar, V. Sulc, J. Berge. System Drop-in Tests of Refrigerant Blends N-13a and AC5 in Bus Air-Conditioining Unit Designed for R-134a. Air-Conditioning, Heating, and Refrigeration Institute (AHRI) Low-GWP Alternative Refrigerants Evaluation Program (Low-GWP AREP), TEST REPORT \#12 (2013).

[49] S. Kulankara, W. McQuade. System Drop-In Test of Refrigerant Blend ARM42a in an Air-Cooled Screw Chiller. Air-Conditioning, Heating, and Refrigeration Institute (AHRI) Low-GWP Alternative Refrigerants Evaluation Program (Low-GWP AREP), TEST REPORT \#14 (2013).

[50] A. Mota-Babiloni, J. Navarro-Esbrí, Á. Barragán, F. Molés, B. Peris. Theoretical comparison of low GWP alternatives for different refrigeration configurations taking R404A as baseline. International Journal of Refrigeration 44 (2014), 8190. 
[51] S.F. Yana Motta, M.W. Spatz, E. Vera Becerra. Low Global Warming Refrigerants for Commercial Refrigeration Systems. International Refrigeration and Air Conditioning Conference (2012). Paper 1351, 14th International Refrigeration and Air Conditioning Conference at Purdue, July 16-19, 2012.

[52] R. Rajendran. Promising Lower GWP Refrigerants In Air-Conditioning And Refrigeration Systems. Retrieved online at: http://www.unep.fr/bangkoktechconference/docs/IIIB-

2\%20Rajan\%20Rajendran_Bangkok\%20Technical\%20Conference\%202013\%2 0Final.pdf, 7 October 2014.

[53] M. Kopecka, M. Hegar, V. Sulc, J. Berge. System Drop-In Tests of Refrigerant Blends L-40, DR-7 and ARM-30a in a Trailer Refrigeration Unit Designed for R-404A. Air-Conditioning, Heating, and Refrigeration Institute (AHRI) LowGWP Alternative Refrigerants Evaluation Program (Low-GWP AREP), TEST REPORT \#9 (2013).

[54] C. Schlosser. System Drop-in Test of L-40, L-41a and N-40b in Ice Machines. Air-Conditioning, Heating, and Refrigeration Institute (AHRI) Low-GWP Alternative Refrigerants Evaluation Program (Low-GWP AREP), TEST REPORT \#2 (2012).

[55] Honeywell Symposium. In: European Heat Pump Summit, 15-16 November 2013, Nuremberg, Germany.

[56] V. Bhanot, D. Bacellar, J. Ling, A. Alabdulkarem, V. Aute, R. Radermacher. Steady State and Transient Validation of Heat Pumps Using Alternative LowerGWP Refrigerants. Paper 2266, 15th International Refrigeration and Air Conditioning Conference at Purdue, July 14-17, 2014.

[57] A. Alabdulkarem, R. Eldeeb, Y. Hwang, V. Aute, R. Radermacher. Evaluation and soft-optimization for R410A Low-GWP Replacement Candidates through testing and simulation. Paper 2256, 15th International Refrigeration and Air Conditioning Conference at Purdue, July 14-17, 2014.

[58] K. Schultz. Performance of R410A and R22 Low GWP Alternative Refrigerants at Elevated Ambient Temperatures. Paper 2381, 15th International Refrigeration and Air Conditioning Conference at Purdue, July 14-17, 2014.

[59] L. Burns, M. Austin, C. Chen. System Drop-in Testing of R-410A Replacements in Split System Heat Pump. Air-Conditioning, Heating, and Refrigeration Institute (AHRI) Low-GWP Alternative Refrigerants Evaluation Program (LowGWP AREP), TEST REPORT \#22 (2013). 


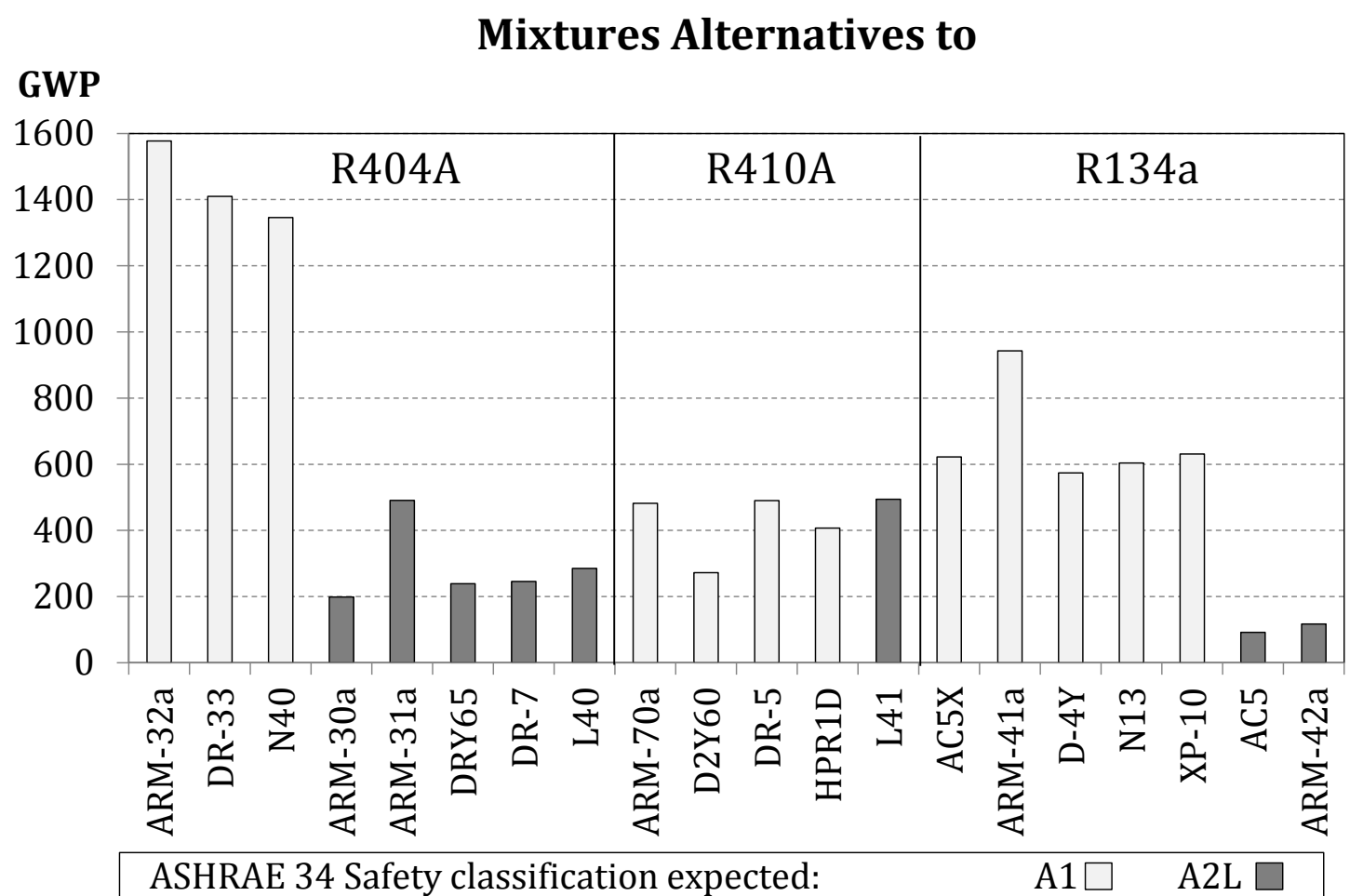

Fig. 1. HFC/HFO mixture alternatives to R404A, R410A and R134a; and their GWP and safety classification. 

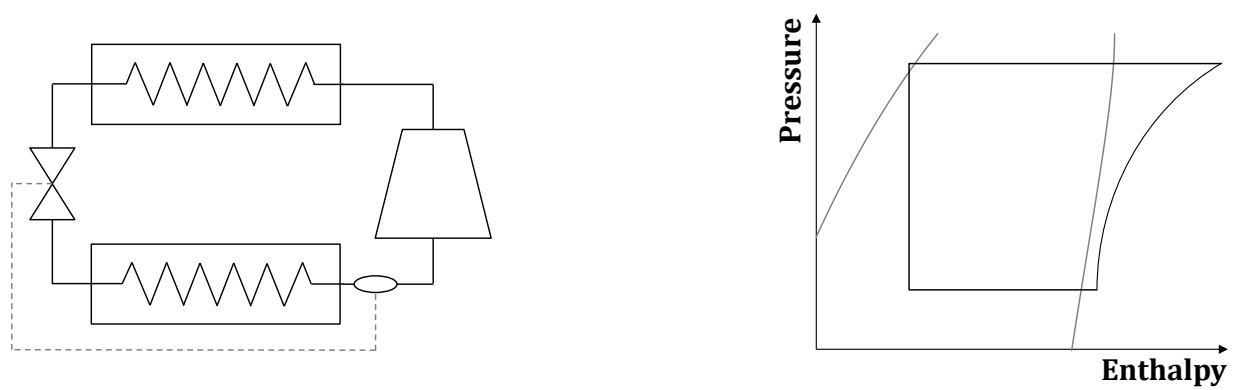

Fig. 2. Diagram and P-h cycle of one stage cycle. 


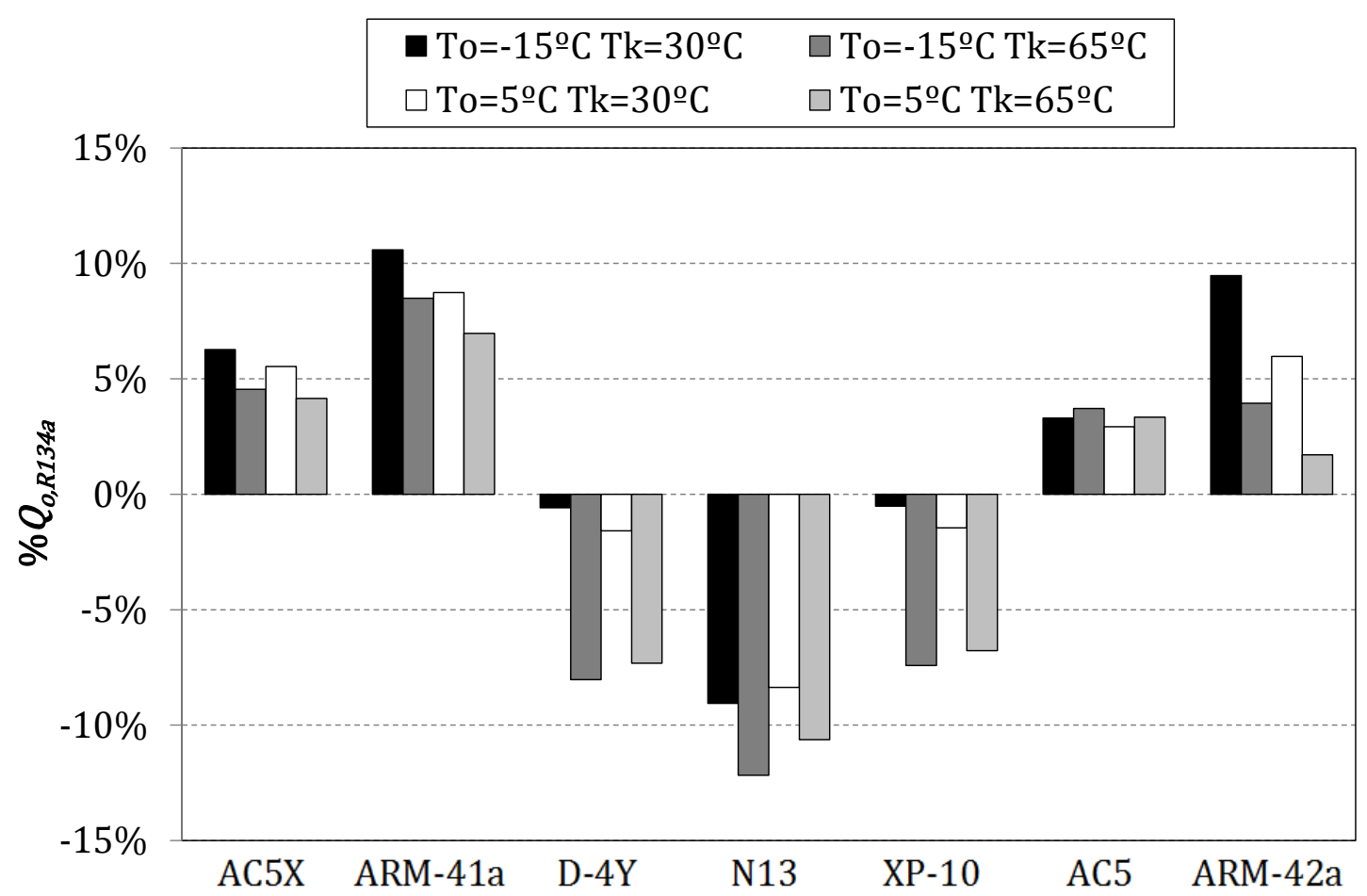

a)

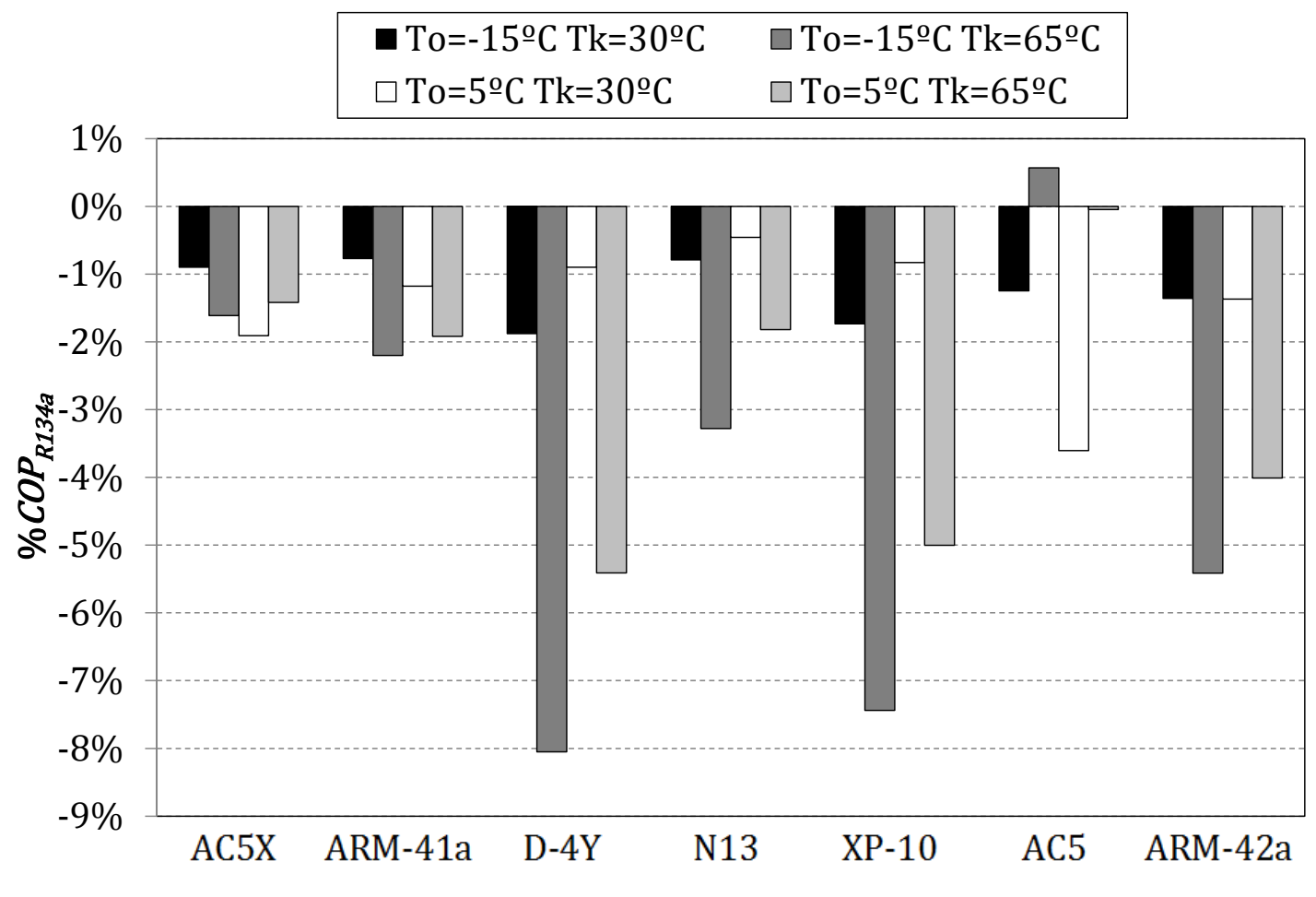

b)

Fig. 3. Results compared with R134a: a) cooling capacity and b) COP. 


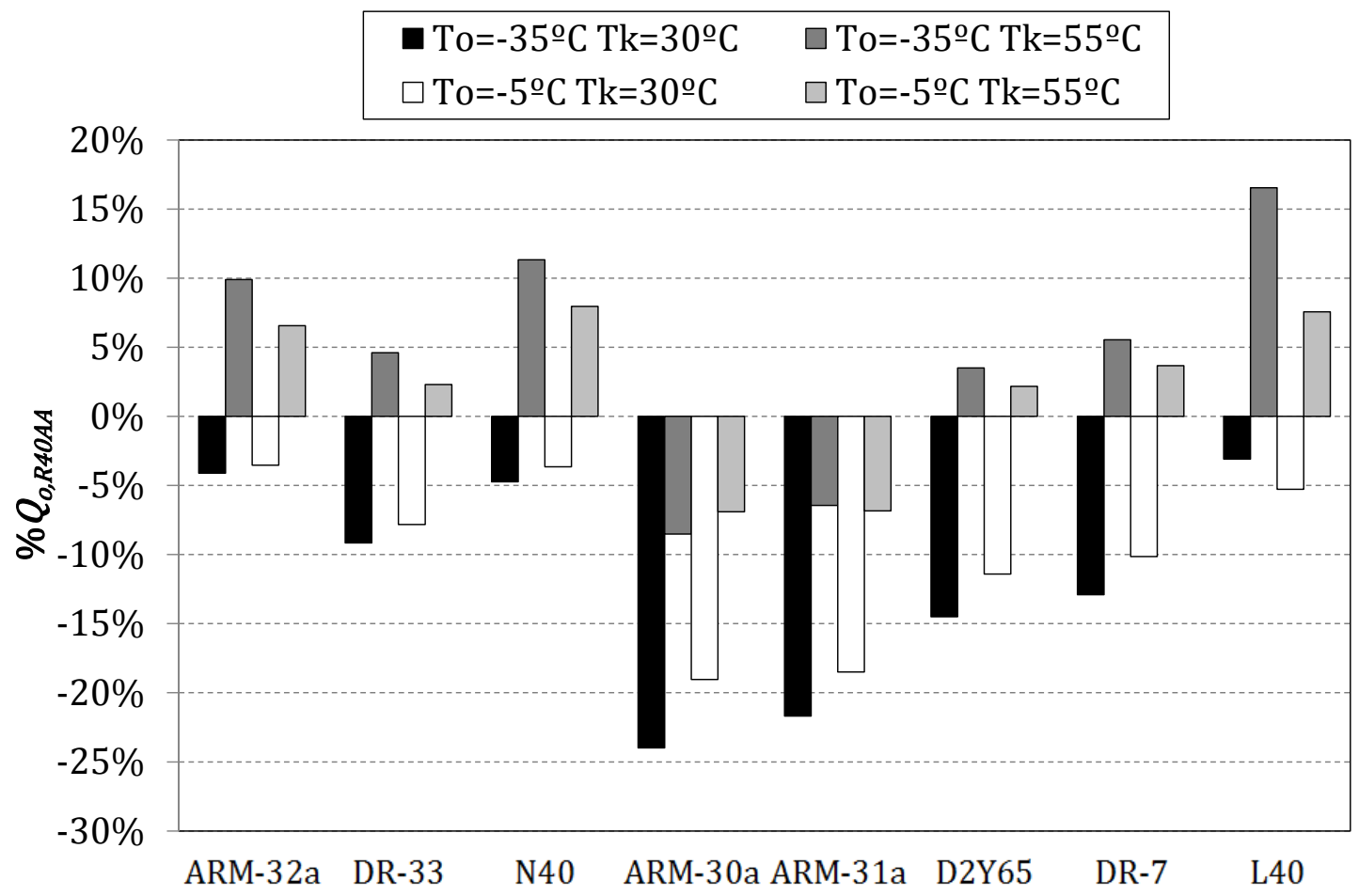

a)

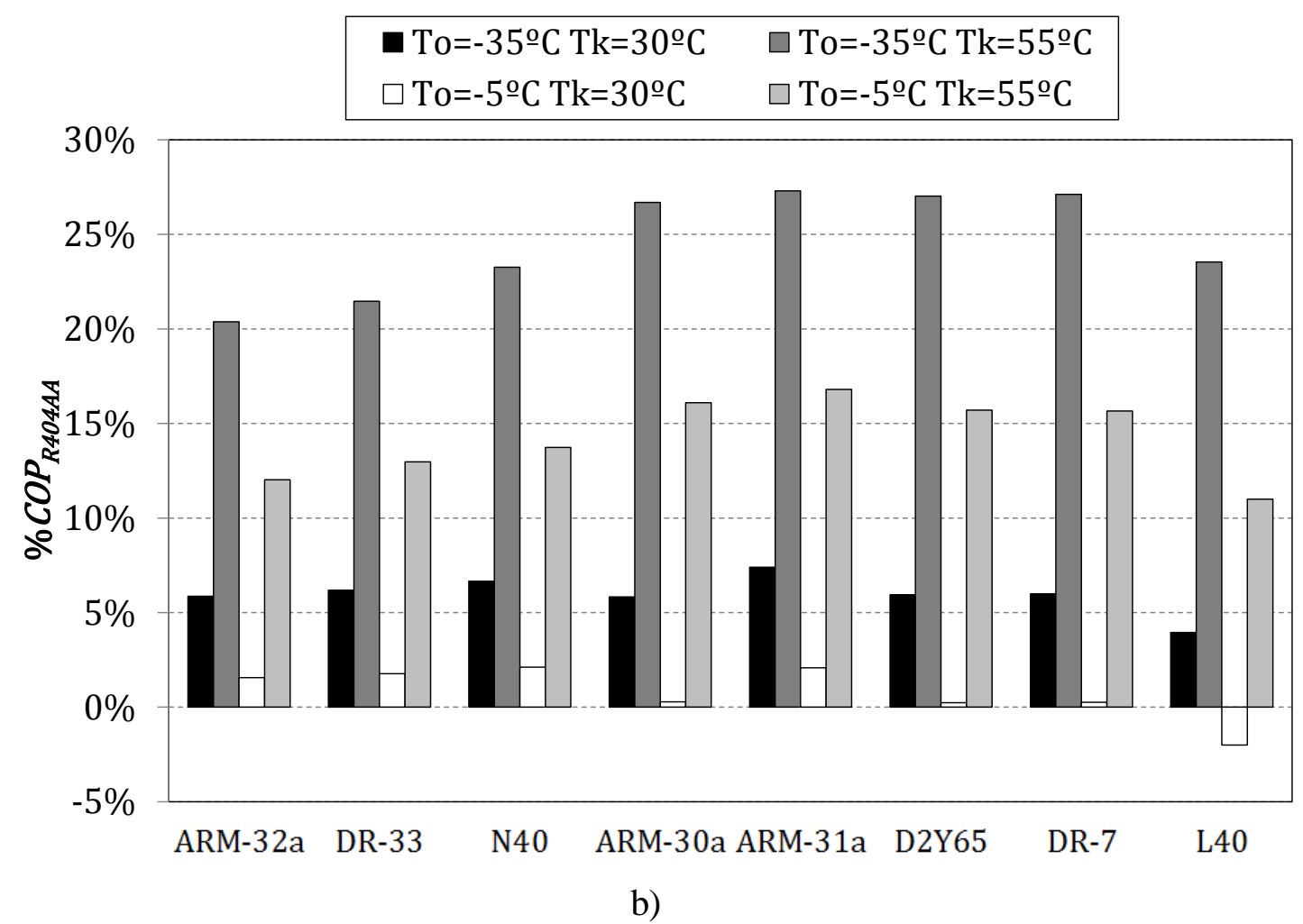

Fig. 4. Results compared with R404A: a) cooling capacity and b) COP. 


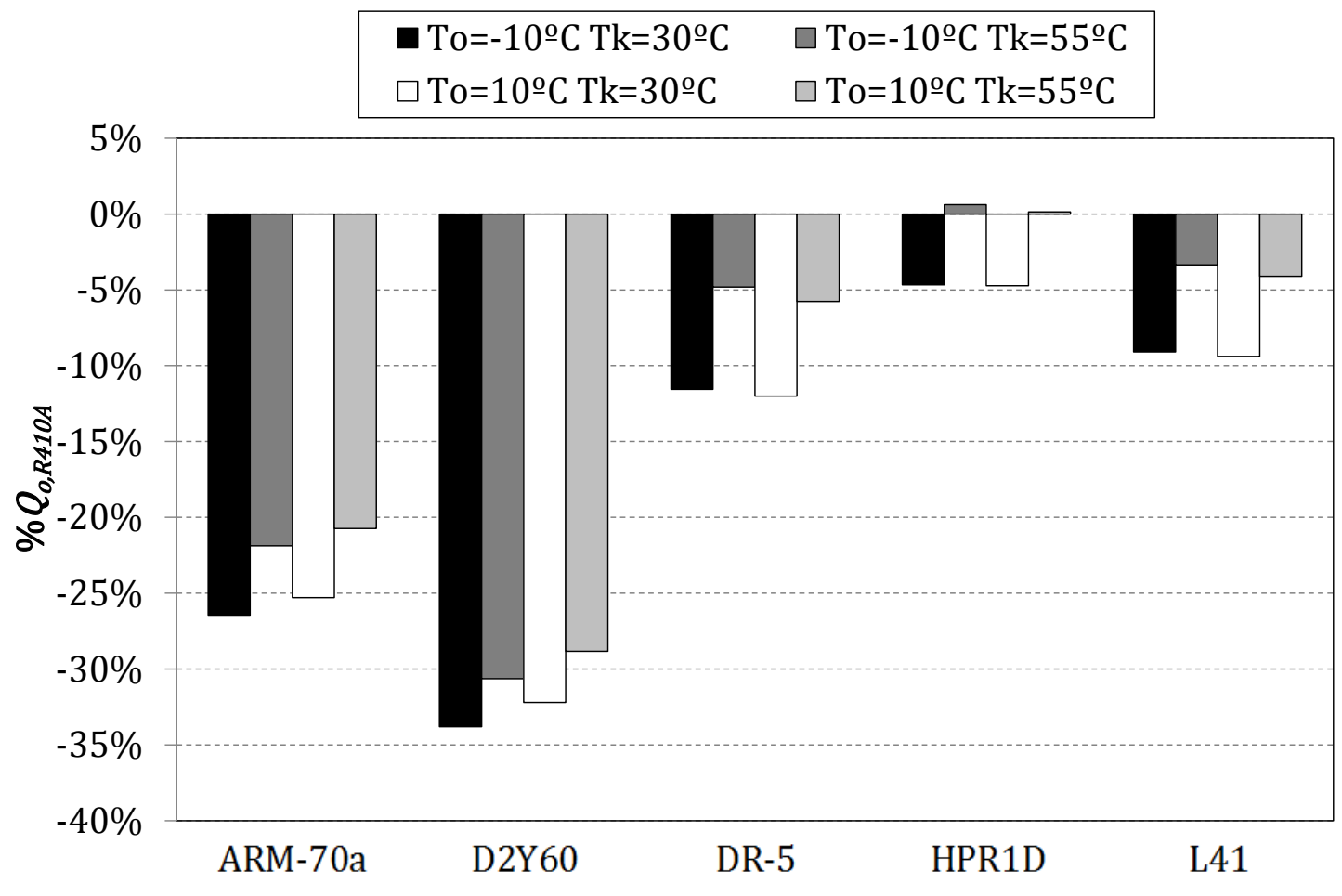

a)

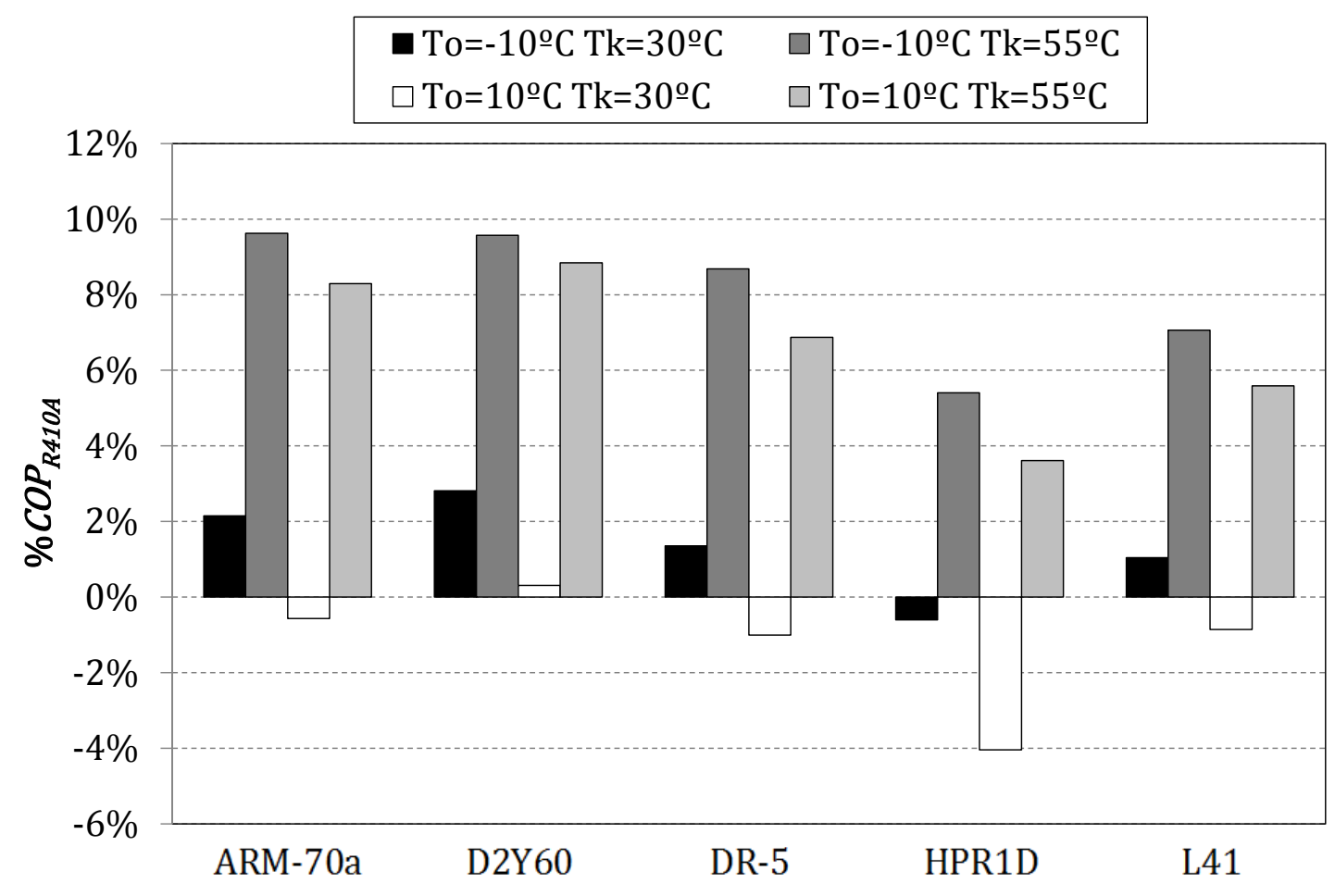

b)

Fig. 5. Results compared with R410A: a) cooling capacity and b) COP. 


\section{FIGURE CAPTIONS}

Fig. 1. HFC/HFO mixture alternatives to R404A, R410A and R134a; and their GWP and safety classification.

Fig. 2. Diagram and P-h cycle of one stage cycle.

Fig. 3. Results compared with R134a: a) cooling capacity and b) COP.

Fig. 4. Results compared with R404A: a) cooling capacity and b) COP.

Fig. 5. Results compared with R410A: a) cooling capacity and b) COP. 
Table 1. Placing on the market prohibitions by the EU Regulation No 517/2014 [3].

\begin{tabular}{|l|c|}
\hline Products and equipment & Date $^{\mathrm{a}}$ \\
\hline Domestic refrigerators and freezers that contain HFCs with $\mathrm{GWP} \geq 150$. & 2015 \\
\hline $\begin{array}{l}\text { Refrigerators and freezers for commercial use } \mathrm{GWP} \geq 2500 . \\
\text { (hermetically sealed equipment) that contain HFCs with }\end{array}$ & 2020 \\
\hline $\begin{array}{l}\text { Stationary refrigeration equipment, that contains, or whose functioning relies } \\
\text { upon, HFCs with GWP } \geq 2500 \text { except equipment intended for application } \\
\text { designed to cool products to temperatures below }-50^{\circ} \mathrm{C} \text {. }\end{array}$ & 2020 \\
\hline $\begin{array}{l}\text { Multipack centralised refrigeration systems for commercial use with a rated } \\
\text { capacity } \geq 40 \mathrm{~kW} \text { that contain, or whose functioning relies upon, fluorinated } \\
\text { greenhouse gases with GWP } \geq 150 \text {, except in the primary refrigerant circuit of } \\
\text { cascade systems where fluorinated greenhouse gases with a GWP }<1500 \text { may be } \\
\text { used. }\end{array}$ & 2022 \\
\hline $\begin{array}{l}\text { Movable room air-conditioning equipment (hermetically sealed equipment } \\
\text { which is movable between rooms by the end user) that contain HFCs with } \\
\text { GWP } \geq 150 .\end{array}$ & 2020 \\
\hline $\begin{array}{l}\text { Single split air-conditioning systems containing less than } 3 \text { kg of fluorinated } \\
\text { greenhouse gases, that contain, or whose functioning relies upon, fluorinated } \\
\text { greenhouse gases with GWP } \geq 750 .\end{array}$ & 2025 \\
\hline
\end{tabular}

a 1 January. 
Table 2. Most commonly refrigerants affected.

\begin{tabular}{|c|c|c|}
\hline Refrigerant (GWP) & Applications & GWP \\
\hline R134a (1430) & $\begin{array}{ll}- & \text { Domestic refrigerators and freezers } \\
\text { - } & \text { Refrigerators for commercial use (hermetically } \\
\text { sealed equipment) } \\
\text { - }\end{array}$ & $\begin{array}{l}150 \\
150 \\
2500 \\
150 \\
1500\end{array}$ \\
\hline R404A (3922) & $\begin{array}{ll} & \text { Refrigerators and freezers for commercial use } \\
\text { (hermetically sealed equipment) } \\
\text { - }\end{array}$ & $\begin{array}{l}150 \\
2500 \\
150\end{array}$ \\
\hline R410A (2088) & $\begin{array}{ll}- & \text { Stationary refrigeration equipment (chillers) } \\
- & \text { Movable room air-conditioning equipment } \\
- & \text { Single split air-conditioning systems }\end{array}$ & $\begin{array}{l}2500 \\
150 \\
750\end{array}$ \\
\hline
\end{tabular}


Table 3. HFC/HFO Mixtures composition by mass percentage.

\begin{tabular}{|c|c|c|c|c|c|c|c|c|}
\hline Baseline & Mixture & R125 & R134a & R152a & R32 & R744 & R1234yf & R1234ze(E) \\
\hline \multirow{7}{*}{$\mathrm{R} 134 \mathrm{a}$} & AC5X & & $40 \%$ & & $7 \%$ & & & $53 \%$ \\
\hline & ARM-41a & & $63 \%$ & & $6 \%$ & & $31 \%$ & \\
\hline & D-4Y & & $40 \%$ & & & & $60 \%$ & \\
\hline & $\begin{array}{l}\text { N13 } \\
\text { (R450A) }\end{array}$ & & $42 \%$ & & & & & $58 \%$ \\
\hline & XP-10 & & $44 \%$ & & & & $56 \%$ & \\
\hline & $\begin{array}{l}\text { AC5 } \\
\text { (R444A) }\end{array}$ & & & $5 \%$ & $12 \%$ & & & $83 \%$ \\
\hline & ARM-42a & & & $11 \%$ & $7 \%$ & & $82 \%$ & \\
\hline \multirow{8}{*}{ R404A } & ARM-32a & $30 \%$ & & & $25 \%$ & & $25 \%$ & $20 \%$ \\
\hline & DR-33 & $25 \%$ & & & $24 \%$ & & $26 \%$ & $25 \%$ \\
\hline & $\begin{array}{l}\text { N40 } \\
\text { (R448A) }\end{array}$ & $26 \%$ & & & $26 \%$ & $7 \%$ & $21 \%$ & $20 \%$ \\
\hline & ARM-30a & & & & $29 \%$ & & & $71 \%$ \\
\hline & ARM-31a & & & & $28 \%$ & & $21 \%$ & $51 \%$ \\
\hline & D2Y65 & & & & $35 \%$ & & & $65 \%$ \\
\hline & DR-7 & & & & $36 \%$ & & & $64 \%$ \\
\hline & L40 & & $10 \%$ & & $40 \%$ & $30 \%$ & & $20 \%$ \\
\hline \multirow{5}{*}{ R410A } & ARM-70a & & $10 \%$ & & $50 \%$ & & $40 \%$ & \\
\hline & D2Y60 & & & & $40 \%$ & & $60 \%$ & \\
\hline & DR-5 & & & & $72.5 \%$ & & $27.5 \%$ & \\
\hline & HPR1D & & & & $60 \%$ & $6 \%$ & & $34 \%$ \\
\hline & $\begin{array}{l}\text { L41 } \\
\text { (R447A) }\end{array}$ & $3.5 \%$ & & & $68.0 \%$ & & & $28.5 \%$ \\
\hline
\end{tabular}


Table 4. Main characteristics of base refrigerants.

\begin{tabular}{|c|c|c|c|c|c|c|}
\hline & R32 & R125 & R134a & R152a & R1234yf & R1234ze(E) \\
\hline $\begin{array}{l}\text { Molecular } \\
\text { mass }\left(\mathrm{g} \mathrm{mol}^{-1}\right)\end{array}$ & 52.02 & 120.02 & 102.03 & 66.05 & 114 & 114 \\
\hline $\mathrm{NBP}^{\mathrm{a}}\left({ }^{\circ} \mathrm{C}\right)$ & -51.65 & -48.08 & -26.07 & -24.02 & -29.49 & -18.97 \\
\hline Critical T $\left({ }^{\circ} \mathrm{C}\right)$ & 78.4 & 66.015 & 100.95 & 114 & 94.7 & 109.36 \\
\hline Critical P (bar) & 53.8 & 36.29 & 40.6 & 47.6 & 33.82 & 36.36 \\
\hline $\begin{array}{l}\text { Gas Density } \\
\left(\mathrm{kg} / \mathrm{m}^{3}\right)\end{array}$ & 2.15 & 4.98 & 4.26 & 2.76 & 4.77 & 4.77 \\
\hline $\mathrm{GWP}_{100-\mathrm{yr}}$ & 675 & 3500 & 1430 & 124 & 4 & 7 \\
\hline $\begin{array}{l}\text { ASHRAE } \\
\text { Safety class. }\end{array}$ & $\mathrm{A} 2$ & A1 & A1 & $\mathrm{A} 2$ & $\mathrm{~A} 2 \mathrm{~L}$ & $\mathrm{~A} 2 \mathrm{~L}$ \\
\hline
\end{tabular}

${ }^{\mathrm{a}}$ at $1 \mathrm{~atm}$ 
Table 5. Simulation conditions.

\begin{tabular}{lccc}
\hline Baseline & R134a & R404A & R410A \\
\hline Evaporation Temperature $\left(T_{o}\right)$ & $-15 / 5^{\circ} \mathrm{C}$ & $-35 /-5^{\circ} \mathrm{C}$ & $-10 / 10^{\circ} \mathrm{C}$ \\
Condensation Temperature $\left(T_{k}\right)$ & $30 / 65^{\circ} \mathrm{C}$ & $30 / 55^{\circ} \mathrm{C}$ & $30 / 55^{\circ} \mathrm{C}$ \\
\hline
\end{tabular}

